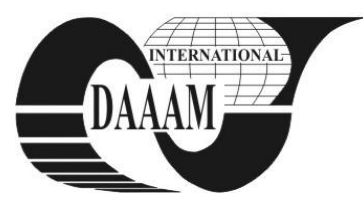

\title{
NATURE CONSERVATION STRATEGY THROUGH A SPATIAL DATA INFRASTRUCTURE
}

\author{
OANA, C[ristina] V[ioleta] \& STAICULESCU, S[imona] L[eontina]
}

\begin{abstract}
One of the main concerns of the European Union Environment policy is dedicated on the deterioration of natural habitats and the threats posted to certain species under the Habitat Directive. Romania is also in the process of developing Spatial Data Infrastructure in response to the Geographic Information 2000 Initiative launched by the European Commission in 1996 and the Infrastructure for Spatial Information in Europe (INSPIRE) initiative launched in 2001. The focus of this article is based on inventorying, mapping natural habitats and wild species of Community interest and implementing a geoportal application to help users to share the geospatial information in the environment and sustainable development sectors.

Key words: geoportals, biodiversity, INSPIRE, metadata, standards
\end{abstract}

\section{INTRODUCTION}

The natural heritage of the Carpathians and the Danube basin are highly important for the entire Europe due to its unique flora, fauna, climate and landscape. As many plants and animal species are under pressure due to the habitat fragmentation and excessive exploitation of the natural resources, Romania is considered one of the European country with the highest numbered of endangered species.

From the European perspective, Romania has to ensure the establishment of Natura2000 network in accordance to the Birds and Habitats Directives and to prepare protection measures for the community interest sites. The management of Natura2000 network is closely related to the natural protected areas and an appropriate management and monitoring system has to be developed and implemented for these areas.

To accomplish this goal, we have built a geoportal application which provides added benefits to environmental planning and decision making and offers improved data to other projects in this environmental sector and to our National Spatial Data Infrastructure.

\section{THE CHALLENGE}

Europe has established an extensive network of protected areas to help protect endangered species and habitat types. However widespread alterations of the landscape coupled with degradation of ecosystems have prevented the EU from meeting its target of halting biodiversity loss by 2010 . At this moment, it does not exist a standard and uniform information system that would allows us differentiation of the specific conservation measures, monitoring and implementation of the management activities and adjustments of the adaptive management percepts.

Unitary systems are developed at the European level in terms of monitoring methodologies and strategies of environment reporting. UK has already developed and implemented a Common Standards Monitoring system to obtain and maintain Favorable Conservation Status for all
Natura2000 sites. France and Germany has also established the monitoring and reporting schemes without implementation of a standard system.

Nevertheless, Romania is in the process to implement a series of the Sectoral Operational Programme "Environment" (SOP ENV) projects that are focused on inventorying and mapping natural habitats and wild species of Community interest for the major natural protected areas. We do consider that our Biodiversity geoportal application will act as a foundation for producing, sharing and consuming biodiversity geospatial information, improving decision making and operations with respect to these issues that are affecting also Europe as a whole.

\section{BIODIVERSITY GEOPORTAL}

In this article are discussed the scientific research studies and implementing a monitoring system of the Natura2000 protected site ROSCI0229 Siriu based on geoportal technology. A geoportal, as indicated by the prefix "geo", is a portal that specializes in geospatial information. A geoportal, also referred to as a spatial portal, is a Web site that provides a single point of access to geospatial data, Web services, and other geospatially related resources. Put more simply, a geoportal is a Web site where geospatial resources can be discovered (Tait, 2005).

\subsection{Geoportal Functions}

The biodiversity geoportal provides functionality to each of the three roles - publisher, administrator and users - associated with it. Publishers provide the content to the geoportal. Administrators manage the content and users could search for contents that meet their specific criteria. The biodiversity geoportal application allows users to perform a search in the following ways:

- Web site: users specify search criteria and review the search results.

- Programming interfaces: the REST interface can return search result in GeoRSS, KML, HTML, HTML fragments and JSON formats.

- Widget: in the geoportal Flex-based Map Viewer.

\subsection{Geoportal Resources Content}

The ROSCI0229 Siriu biodiversity geoportal incorporates the following:

- Framework datasets - including nine themes: topographic basemaps, orthoimagery, elevation, geology, hydrography, transportation, administrative units, protected area sites, hydrological constructions.

- Operational layers (or thematic layers) - show items of natural habitats and wild species of community interest on top of a basemap in order to monitor the Favorable Conservation status. The geoportal offers a variety of the geospatial web services from ArcGIS Online, ROEnv Geoportal application hosted by Ministry of Environment 
and Forestry and INIS GeoPortal managed by Ministry of Interior and Administration. All these available web map services can be mashed up and allow users to make it easier, quicker and cheaper their own GIS application related to biodiversity.

\subsection{Metadata standards}

Metadata, or "data about data", is the information that describes other data. Geospatial metadata refers to the information that describes geospatial data, Web services, or other geospatial resources. There is object-level metadata, which describes a single entity, and collection-level metadata, which describes a series or a group of entities (Goodchild \& Zhou, 2003).

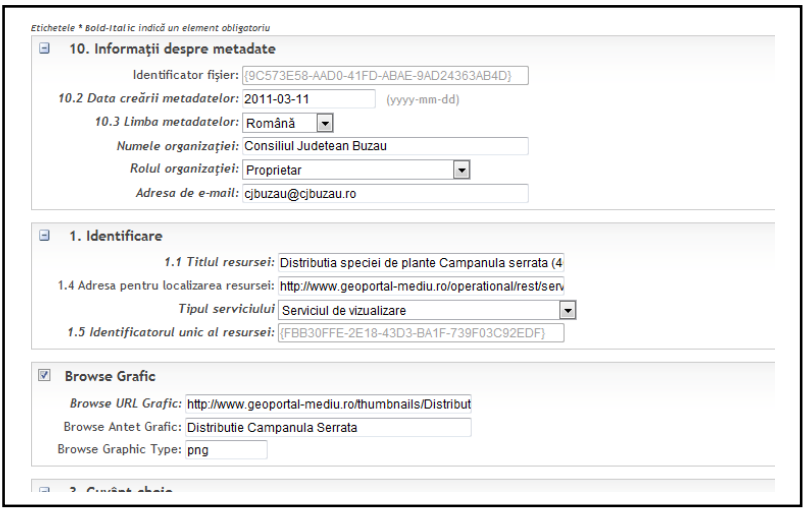

Fig. 1. ROSCI0229 Siriu Geoportal - Metadata Editor

Geospatial metadata published to the biodiversity geoportal catalog includes the following elements: resource identification, quality and validity, spatial reference, temporal and distribution information. Metadata is useful in data archiving, assessment, management, discovery, transfer and distribution to users. In the geoportal context, metadata has the following uses (Longley et al., 2005; Van Oosterom and Zlatanova, 2008): discovery, evaluation and use of resources and the contract terms between the user and the publisher. The Inspire implementing guidelines are based on EN ISO 19115 (datasets) and EN ISO 19119 (services) for Commission Regulation (EC) No 1205/2008 of 3 December 2008 implementing Directive 2007/2/EC of the European Parliament and of the Council as regards metadata (2010).

\subsection{Interoperability of spatial datasets and services}

The ROSCI0229 Siriu biodiversity geoportal supports the following standards:

- Data models - Implementing Rules for the Annex I.

- Metadata standards - ISO 19115, ISO 19139, ISO 19119, Dublin Core, INSPIRE Profiles.

- Standard interfaces that enables users to discover resources through geoportal: Open Geospatial Consortium, Inc. (OGC) for Web (CSW), CSW ISO AP, Inspire Discovery service, REST, OpenSearch.

- Interface standards - for integration with external map services such as: Esri ArcGIS Server; KML/KMZ; GeoRSS; Open Geospatial Consortium, Inc. (OGC) WMS, WFS and WCS.

- Interface standards - for catalog service harvesting such as: Open Geospatial Consortium, Inc. (OGC) for Web (CSW), XML under Web-accessible folders (WAF), the Esri metadata service and the Open Archive Initiative (OAI).

\section{NEXT STEPS}

The next research step of our Biodiversity geoportal application is under development process to extend its capabilities to fully support the management planning process of all series of the Sectoral Operational Programme "Environment" projects that are focused on inventorying and mapping natural habitats and wild species of Community interest for the natural protected areas. Our best practices are open to new and innovative ideas in order to sustain this cyclical, iterative and developmental process of the management planning for the nature conservation sites.

Another issue of the next developments is addressed by the harmonization of key spatial data themes across Ministry of Environment and Forestry and NSDI Council to support the European environmental policies.

\section{CONCLUSION}

However, addressing the complexity of biodiversity remains a challenge and it is acknowledged that there are still significant knowledge and data gaps in many areas. In the coming years, it will be important to ensure that biodiversity research and monitoring within the EU and globally is stepped up to fill these knowledge gaps. This will create a more robust and comprehensive knowledge base for supporting future policies and actions, which should ultimately result in more efficient and effective policy making.

Our Biodiversity geoportal application that is based on a Web-oriented architecture (WOA) facilitates information sharing and collaboration, including the bottom-up flow of information, open and interoperable Web services, mashups, cloud computing, geobrowsers. All of these technical advantages should work in favor of our National Spatial Data Infrastructure (NSDI) and provides support for building blocks of the European Commission's Shared Environmental Information System (SEIS).

\section{ACKNOWLEDGEMENTS}

The authors wish to acknowledge the contributions and support from our scientific project experts - Multidimension and Ministry of Environment and Forestry and Buzau County Council. The project is under the Sectoral Operational Programme Environment - Priority Axis 4: "Implementation of adequate management systems for nature protection".

\section{REFERENCES}

Dihoru, Gh. (1975). The vegetal cover from Siriu Mountain, The Romanian Academy, Bucharest.

Oltean M.; Negrean G., Popescu A., Roman N., Dihoru G, Sanda P., Mihăilescu S. (1994). Red List of higher plants from Romania, Institute of Biology of the Romanian Academy, Bucharest.

Goodchild, M. F.\& Zhou, J.. (2003). Finding geographic information: Collection-level metadata. GeoInformatica, Vol., 7., (2) 95-112

Longley, P. A.; Goodchild, M. F., Maguire, D. J. \& Rhind, D. W. (2005). Geographic information systems and science, 2nd ed., John Wiley\& Sons, San Francisco

Tait: Michael G. (2005). Implementing geoportals: Applications of distributed GIS, In: Computers, Environment and Urban Systems, 29 (1) 33-47

Gafta, D.; Mountford, O. (2008). Manual of the Natura2000 Habitats, Ministry of Environment, ISBN 978-973-751697-8, Risoprint Cluj Napoca, Available from: http://www.coastal-biodiv.ro, Accessed on: 2011-03-31

*** (2011) http:// geoportal-mediu.ro/home/index.html ROSCI0229 Siriu Biodiversity Geoportal application, Accessed on: 2011-03-31 